\title{
Feng Shui in Science Programmes
}

\section{Philosophical, Cultural and Educational Considerations}

\author{
Michael R. Matthews ${ }^{1}$
}

Accepted: 3 September 2021 / Published online: 6 October 2021

(c) The Author(s), under exclusive licence to Springer Nature B.V. 2021

Feng shui is a set of beliefs and practices arising from a two-to-three-thousand-year-old deeply entrenched Chinese and East-Asian worldview and cosmology. Feng shui has long migrated from Asia and has an increasing international commercial, cultural and social presence. ${ }^{1}$ Amazon has 7000 feng shui books listed in English alone. A Google FENG SHUI search returns one-hundred-million-plus sites in half-a-second. The web sites support a multi-billion-dollar industry. The worldview that anchors feng shui also anchors Traditional Chinese Medicine (TCM) and Traditional Korean Medicine (TKM) both of which are institutionalized with university medical schools, certification, government registration, laws, and much else. In China, 240 universities offer degree programmes in TCM while 18 countries have included acupuncture in their medical insurance schemes.

In the West, these practices are known as Alternative Medicine, Complementary Medicine, and Holistic Medicine. Collectively they are referred to as 'Complementary Alternative Medicine' (CAM); increasingly they are a component of university medical programmes. The worldview of feng shui supports and justifies a spectrum of health practices: Qigong, Falun Gong, Tai Chi, and Jin Shin Jyutsu. They all combine chi (qi) with gong, meaning work, practice, or exercise. Each day, many millions of people worldwide perform these exercise regimes with either more or less attention to their underlying fengshui-shared rationale.

A study of feng shui in Korea commenced with the statement: 'The importance of geomancy [divination or foretelling the future] in understanding the East Asian cultural landscape and cultural ecology is difficult to overemphasize' (Yoon, 2006, p.xiii). Four hundred years earlier, Matteo Ricci (1552-1610) the Sinophile leader of the famed late-sixteenth century Jesuit mission to China (Laven, 2011), wrote in his Travel Journal:

In choosing a place to erect a public edifice or a private house, or in selecting a plot of ground in which to bury the dead, they study the location with reference to the head and tail and the feet of the particular dragons [chi lines] which are supposed to dwell beneath that spot. Upon these local dragons they believe that the

1 Feng shui's origins, history, philosophy, and applications have been exhaustively written upon. See at least Matthews, 2019 and its 1200 references.

Michael R. Matthews

m.matthews@unsw.edu.au

1 School of Education, UNSW, Kensington, Australia 
good and bad fortune, not only of the family but also of the town and province and the entire kingdom, is wholly dependent. Many of their most distinguished men are interested in this recondite science and, when necessary, they are called in for consultation, even from a great distance. ... Just as their astrologers read the stars, so their geologists [diviners] reckon the fate, or the fortune of a place, from the relative position of mountains or rivers or fields, and their reckoning is just as deceitful as the reading of the stargazers. (Ricci 1615/1953, p.84)

\section{Chi: The Foundation of Feng Shui}

The ontological core of feng shui theory and practice, and more broadly of TCM, TKM and CAM, is commitment to the reality of an all-encompassing cosmic life-force, or energy, called chi (qi). This has been a central and culturally defining Chinese belief for three millennia. It is akin to belief in God for the Judaic, Christian, Islamic world. Until recent centuries, most people in those nations and countries believed in a Deity. So too, in China and other Asian traditions, there was comparable belief in chi, or some equivalent universal 'life force'. The difference between the Abrahamic traditions and the Asian traditions is that the Deity, although able to intervene in earthly affairs as they saw fit, or in response to personal petition (prayer), was supernatural whereas chi is natural and impersonal; it is understood as a part of nature, part of the furniture of the world. Deism, where God first creates then leaves alone, is the closest theist tradition to Asian chi belief, but even that is not very close. Further, chi functions in a lawful manner comparable to gravitation or other acknowledged universal mechanisms. Chi cosmology is legal; chi is part of a legal, law-governed framework.

Feng shui theory and practice cannot be understood apart from this universal 'life force'. Chi ( $q i$ ) is the foundation of Chinese cosmology, town planning, architecture, personal well-being, health, martial arts, medicine, and also the widespread practice of geomancy — the identification of auspicious burial and building sites. It is the basis of divination, the ascertaining of individual good or bad fortune.

Joseph Needham, in his monumental multi-volume Science and Civilization in China, records that:

Besides divination based on the heavens, the Chinese also used methods that depended on the Earth, methods of geomancy or feng-shui. The basic idea was that if the houses of the living and tombs of the dead were not properly positioned, then evil effects of the most serious kind would affect the inhabitants of the houses and the descendants of those whose bodies lay in the tombs. (Needham, 1978, p.178)

Two Chinese philosophers affirm:

$Q i$ is one of the most important and widely interpreted concepts in Chinese intellectual history. As a shared notion underlying all schools, $q i$ is believed to be a dynamic, all-pervasive, and all-transforming force animating everything in the universe. The air one breathes, the force that drives the flow of blood, the food one eats, the strength of one's mind, the flow of one's thoughts, the deepest urges of one's heartall of these are understood in terms of $q i$. Thus, qi extends across realms that might otherwise be divided into the spiritual, mental, or physical. (Wang \& Ding, 2010, p.42) 
An authoritative modern Chinese Philosophy text written by Zhang Danian, Beijing University Philosophy Department, devotes a chapter to chi. It provides an informative listing of scores of representative and influential Chinese chi beliefs from ancient times to the present (Zhang 2002). Ken Tobin a world-leader of the constructivist movement in science education and the recipient of numerous education-research prizes, has embraced chirelated medical practice, saying:

The underlying theory relates to Qi, universal energy, and its flows through the body. In the case of humans there are 26 pairs of safety energy locks (SELs) through which Qi flows, providing the life source to the body ... When a body is disharmonized, energy can be blocked at or close to the SELs, thereby disrupting one or more of the flows needed to distribute the life force to different parts of the body. (Tobin, 2015)

That someone of Tobin's repute in science education writes so easily of chi flowing through the body and being manipulated by acupuncture and hand pressure, is a measure of how 'normalised' feng shui has become. It might also be a measure of how credulous feng shui commentary has become and how needful attention to informed history and philosophy of science has become.

Simon Brown, the author of The Feng Shui Bible, gives an account of chi similar to what can be found in multiple thousands of popular books on the subject:

Chi is the subtle charge of electromagnetic energy that runs through everything, carrying information from one thing to another. The chi flowing through your body predominantly carries your thoughts, beliefs and emotions. At the same time some of your chi is floating off, while you are also drawing in new energy. ... Your energy field connects you to everything else, whether you like it or not. The secret to making this energy work is understanding the process and finding out how you can make it help you in life. (Brown, 2005, p.24)

Comparable claims are repeated on hundreds of thousands, if not millions, of feng shui websites. Seemingly, everyone is buying or selling either a piece of, or information about, chi. Predictably, thousands of websites are selling chi-based Covid cures. All of this constitutes the parallel industry and science of feng shui. Whether it is a parallel science and business or parallel pseudoscience and racket are questions addressed in contributions to this journal issue.

Just as in the West, where not all believed in the existence and interventions of the supernatural, so also in China and Asia there was, and is, a dissenting chi tradition. In the West and Islamic world, belief in the Deity was a religious matter. In the Asian tradition, commitment to chi was just a decision about how the world was; it was a matter of worldviews, not religion; chi was impersonal, it was simply a part, albeit a special part, of the furniture of the world. Although the chi worldview carried with it guidance for how and where life was best lived, how and where parents should be buried, how homes need be arranged and decorated - these were more life-style matters than religious ones. When paid considerable amounts of money, feng shui consultants proffered the guidance; and for large constructions, they signed off on it. But there was not universal commitment to the chi worldview.

In 1915, in the turbulent political and ideological times following the collapse of the Manchu dynasty and establishment of the new Republic of China, a hugely popular and influential periodical, New Youth (La Jeunesse Nouvelle), was launched. It was edited by Ch'en Duxiu (1879-1942), a noted champion of science, critic of traditional Confucian 
philosophy and culture, and a founder of the Chinese Communist Party (CCP). Its opening editorial opined:

Our men of learning do not understand science; thus they make use of yin-yang signs and beliefs in the five elements to confuse the world and delude the people and engage in speculations on geomancy ... The height of their wondrous illusions is the theory of Ch'I [primal force] ...We will never comprehend this $C h$ 'I even if we were to search everywhere in the universe. All of these fanciful notions and irrational beliefs can be corrected at their roots by science, because to explain truth by science we must prove everything with fact. Although this is slower than imagination and arbitrary judgment, every progressive step is taken on firm ground. It is different from those flights of fancy which in the end cannot advance one bit. (New Youth, 1915, vol.1, p.1. In Kwok, 1965, p.65)

One hundred years later, this thematic issue is, in part, an appraisal of the claim made by Ch'en: Is feng shui consistent or inconsistent with science? And what are the attendant philosophical, cultural and educational considerations that follow from the answer?

\section{Contributions}

Damian Fernandez-Beanato recognises that the first step in the philosophical consideration of feng shui is the Demarcation Problem. That is, to consider whether its theory and practice constitutes a normal mature science like chemistry; whether it is a proto- or beginning or could-be science; whether it is more properly a non-science much like art or music; or is it a pseudoscience that asserts truth claims about world by following a scientific method, but actually does not do so.

He argues that a first step for scientific demarcation is the composition of a broad "list" (set) of accepted characteristics, conditions, or properties of science, or indicators of scientificity which might be collectively used to establish a demarcation between those theories, cognitive fields, practices, etc. which are scientific and those which are not. This is an 'exemplary case' method of proceeding. When inquiring into what constitutes science, the beginning is to point to examples of things which everyone takes to be science; to examine exemplary cases and see what they reveal. Newtonian physics would be one such case; if that is not science, then the question of what is science has no meaning.

Fernandez-Beanato refers to Mario Bunge's proposed ten-point list for the identification of science whereby a mature science is characterized by:

- A community (C) of appropriately trained inquirers with recognized public means of information exchange.

- A general outlook or philosophical background (G) that includes an ontology of discernible things, a realist epistemology, and an ethos supporting the free search for truth.

- Its domain of investigation (D) is real events and processes in the world, not texts and not ideas, though, of course, the latter are utilized.

- Its formal background $(\mathrm{F})$ is a collection of current best logical and mathematical theories about D.

- Its specific background (B) is a collection of up-to-date and reasonably well confirmed data, hypotheses and theories from other fields relevant to $\mathrm{F}$. 
- Its problems or puzzles $(\mathrm{P})$ consists of cognitive rather than practical matters concerning items and events in $\mathrm{D}$, being usually a quest for laws.

- Its fund of knowledge $(\mathrm{K})$ is a collection of up-to-date and testable (though not final) theories, hypotheses, and data compatible with $\mathrm{B}$.

- Its aims or goals (A) are the discovery of laws or confirmed hypotheses about elements of D.

- Its methods (M) consist exclusively of scrutable, checkable and justifiable procedures; there need not be commitment to a single method.

- It has a significant overlap $(\mathrm{O})$ with other scientific fields of inquiry such that there are overlaps in the respective G, D, F, B, P, K, A, M sets. A mature science does not exist in cognitive isolation from other mature sciences; they learn from and feed off each other. (Bunge, 2001, pp. 170-171)

That is, for Fernandez-Beanato and Bunge, sciences are defined by subject matter, ontologies, epistemologies, methodologies, internal organization, and external disciplinary and institutional connections. No science is an island. All of these features are part of science; and none can be taken in isolation. So, attempts at just philosophical, or just sociological identification and demarcation do not work. Fernandez-Beanato endorses Bunge's programme and elaborates it, providing 36 characteristics or features of scientificity, none of which alone can be said to be either necessary or sufficient for demarcation. He gives close attention to feng shui theory and practice concluding that feng shui lacks 33 of the identified 36 characteristics and hence cannot be meaningfully labelled science.

Ínigo Ongay presents a philosophical appraisal of feng shui's best known and most institutionalized dimension, namely Traditional Chinese Medicine (TCM). He notes that, as is generally the case with other versions of Traditional- or Ethno-Medicines, rather than a coherent research program TCM is not a unified theory. It constitutes a promiscuous array of various techniques and practices coupled with a diversity of very different speculative doctrines regarding the physiological structure of certain body parts as well as the purported etiology of disease and malfunction. Instead, TCM constitutes a rather disunified array of clinical practices and theoretical commitments ranging from acupuncture to herbal medicine all predicated on the understanding of $q i$ (氣) as an all-pervasive form of energy that governs the functioning of the body.

Ongay recognizes that if the notion of success is defined in a sufficiently broad manner there is no doubt that acupuncture and a variety of different forms of Chinese herbal therapy are socially successful. After all these practices have endured for long periods of time and still continue to do so, which would not be expected to happen unless a significant number of patients felt better, or even got better, upon utilizing the services. But the 'feel better' effects can be accounted for by well-established social psychology and equally wellestablished placebo effects.

Michael Paton treads a path between the somewhat opposite conceptions of the science in fengshui between Eastern and Western scholars. He stresses that there is a physical or material element inherent in early fengshui writings citing the $300 \mathrm{CE}$ Book of Burial that relates how 'If $q i$ rides the wind (feng) it is scattered; if it is bounded by water (shui) it is held' and so the ancients gathered it, causing it not to be scattered and curtailed its area of circulation. This is a very physical understanding of $q i$ from whence the name feng shui derives.

Paton stresses that early fengshui theory was based on observation of the relationship between landform and agriculture fertility. The cosmology of the Book of Burial, for instance, only included the concepts $q i$ and yin/yang, the form and configurational force of 
the topography and the emotional response to this. However, as the theory developed more and more of the vast array of Chinese cosmology was overlain on this original comparatively simple empirically based scheme, including five-phase theory, the trigrams of the $\mathrm{Yi}$ Jing, Chinese astrology, the celestial stems and terrestrial branches.

Jinwoong SONG, Jieun CHUN, and Jiyeon NA note that in contemporary society, people are expected to make scientific decisions and engage in rational action over a range of personal and social problems. They present a case study of how this is done in Korea, drawing attention to the national flag that embodies the dual forces of nature in the classical Asian view. The red and blue circle in the middle of the flag is called taegeuk in Korean ( $t$ 'ai chi in Chinese). The circle is divided into two parts with the upper red part representing the forces of yang (yang in Chinese as well), and the lower, blue part representing the forces of um (yin in Chinese). The feng shui worldview is embedded in the country's flag (Lee, 2006).

In Korea, the academic foundation of Traditional Korean Medicine (TKM) and acupuncture is institutionalised. The Journal of Acupuncture Research is a professional journal that publishes the results of clinical observations and treatments in the form of research papers, and the Korea Institute of Oriental Medicine is a governmental research institute that carries out various research and patent activities on TKM drug tests, health diagnosis, and experimental methods. Thus, if scientificity is identified in a purely sociological manner, TKM is scientific - it has peer-reviewed journals, professional societies, external funding, etc. But this conclusion only means moving the debate one step down to then ask is TKM scientific in the same way Western or Modern International Medicine (MIM) is scientific?

Sindhuja Bhakthavatsalam and Weimin Sun argue for a virtue epistemological approach to the vexing demarcation problem (Baehr, 2016; Zagzebski, 1996). This approach makes the most sense in terms of identifying and ameliorating epistemological commitments that foster pseudoscientific and anti-scientific stances. They argue that sustained and consistent pseudoscientific beliefs and attitudes call for an explanation in terms of underlying epistemic vices, and that remedying them calls for charging the relevant people with epistemic vice, but in a responsible and sensitive way.

They endorse Anthony Derksen's project of seeking practitioner-based demarcation criteria rather than discipline or theory-based criteria: "I place the emphasis on the pseudoscientist, because it is a person, and not a theory or a field, who can have scientific pretensions, and who can be blamed for not making good these pretensions." (Derksen, 1993, p. 21). Further, instead of necessary and sufficient demarcation criteria as required by Laudan, Derksen gives an 'epistemic-social-psychological profile' of a pseudoscientist. Elaborating such profiles leads to even more fundamental investigations, namely intellectual qualities of the mind. Virtue epistemology - a relatively new branch of epistemology — provides a conceptual framework for productive discussion about pseudoscientific practices.

Kai Ming KIANG and Wai Man SZETO describe teaching about Traditional Chinese Science (TCS) and the Nature of Science (NOS) in a large 2000-student General Education foundation course titled In Dialogue with Nature they teach in the Chinese University of Hong Kong. The course is partly based on 16 readings from classic works in the history of science (Plato, Newton, Darwin, Newton) and writings by historians and philosophers about those works.

They give an account of: (i) introducing the foundational concepts of TCS, including $q i$, yinyang and wuxing; (ii) explaining why it is debatable to consider TCS as scientific; (iii) how TCS is taught and used in class discussions; (iv) how evaluation of the performance of the students was conducted; and (v) what students learn from the course. Students also 
engaged in the Needham Question (Sivin, 1984): Why did China not have its own scientific revolution? Students usually identified the unwillingness of ancient Chinese to challenge existing knowledge, and value system controlled by the authorities, as the answer to this question. This is the conservatism of the Confucian tradition.

Meifang ZHANG and Bing LIU address the pressing question of: How to integrate science and traditional culture in contemporary Chinese science education? They focus on the rationale, preparation, content and reception of the draft National Benchmark for Scientific Literacy of Chinese Citizens released by the Ministry of Science and Technology in 2016 (MST, 2016). The Benchmark debates can be traced to historical discussions in China, regarding the relation between science and humanities, the boundaries of science, and the goals of science education. Zhang and Liu recognize that in the Chinese concern for modernization since 1840 s, the gap between scientific and humanity studies persists, with versions of scientism still dominating the dialogue.

\section{Feng Shui and Teaching about Energy}

Given the centrality of 'energy' in feng shui theory and practice, and given the wide influence and impact of feng shui thinking in Asian and now Western culture, the subject of energy is a natural context for consideration of feng shui in science programmes. Energy is the central conceptual component of modern science - all modern science, not just physics (Coopersmith, 2010; Sherman, 2018). There are as many types of energy as there are types or classes of natural processes: kinetic, potential, magnetic, nuclear, chemical, and so on. Energy is a property of all existent things; hence it is universal. But it does not exist apart from things of which it is a property (Bunge, 2000). Einstein's 'most famous equation in the world' $-\mathrm{E}=\mathrm{mc}^{2}-$ unites energy with mass; energy with something (Lange, 2001). There is no 'free-floating' energy — if there is no $\mathbf{m}$, there is no $\mathbf{E}$. Consequently, if a putative $\mathbf{E}$ has no $\mathbf{m}$, then it is not a scientific $\mathbf{E}$ and cannot enter into causal chains and energy transfers; 'all bets are off', and anything can be said about or claimed for it provided the claims are recognized as fantasy. For the sake of clarity it could be referred to as $\mathrm{E}^{*}$, a non-scientific $\mathrm{E}$ about which, like in fairy tales, anything can be said, and about which dispute is pointless.

In China, the Ministry of Science and Technology in 2016, issued a Bulletin detailing 132 points that are deemed to constitute Chinese Citizens' Scientific Quality Standards (MST, 2016). These understandably include:

(52) Knowing the law of conservation of energy, energy will neither be generated nor destroyed, it will only be transformed from one form to another, or transferred from one object to another, while the total amount remains unchanged.

Additionally, the Bulletin lists:

(9) Knowing the traditional Chinese philosophical concepts such as Yin and Yang, the five elements, the unity of heaven and man, and knowledge-giving to knowledge is the simple materialism and overall systematic methodology of ancient China and has practical significance.

Unfortunately the scientific, philosophical, and educational questions posed by the juxtaposition of (52) and (9) are not addressed. 
In 2012, in the USA the Department of Energy (DoE) produced an educational guide that specifies an 'energy literate' person has:

An understanding of the nature and role of energy in the universe and in our lives.

Energy literacy is also the ability to apply this understanding to answer questions and solve problems. (Department of Energy, 2012, p.4)

The Guide further elaborates that such a person 'Can assess the credibility of information about energy'. The US Next Generation Science Standards explicitly link the understanding of energy to understanding the nature of science; indeed, to being scientific (NGSS Lead States, 2013, HS-PS1-7). Both Chinese and US aspirations for the scientific literacy of their citizens can be advanced by explicit treatment of feng shui in science classes.

For instance, all students should, after an adequate teaching programme about energy, be capable of an informed comment on the much-reported claims made about the celebrity super-Qigongist Dr Yan Xin who is a former TCM practitioner who worked in different Chinese and USA universities (Yan, 2015). He has an international reputation for healing thousands of patients at a distance by generating and casting his own qi over them. Some of his lectures, including in US universities, were attended by tens of thousands. In 1986 he was attached to the Qigong Cooperative Research Group at Tsinghua Technical University in Beijing. There he claimed:

The mind power or $Q i$ emitted by a trained Qigong master can influence or change the molecular structure of many test samples, including those of DNA and RNA, even if these test samples are 6 to 2,000 kilometers away from the master. $Q i$ can also affect the half-life of radioactive isotopes and the polarization plane of a beam of light as emitted from a Helium-Neon laser. (Yan et al., 2002)

In a 30-page 2002 paper in The Journal of Scientific Exploration, co-authored with ten Chinese and US scientists from prestigious universities, the claim is made that:

According to the different circumstances, external qi of Dr. Yan Xin can display different attributes such as being distance transcending, bi-directional, reversible or targeting. Although external qi of Yan Xin Life Science Technology has not been identified with any of the four known and accepted fundamental physical forces, its influence on physical reality is robustly confirmed. (Yan et al., 2002, p.381)

These remarkable claims have an unmistakable 'ring' of science about them, and there have been studious efforts to 'scientifically' support them. None are convincing. There is a stark choice: Maintain the cornerstone of science or embrace chi. Having both is, objectively, not possible, though manifestly it is subjectively possible. A US professor, and head of a university psychology department, wrote regarding this special issue: 'I've practiced qigong. I find it to be meditative and beneficial, regardless of any metaphysical assumptions or claims. There is a palpable energy that I can subjectively appreciate while practising, or indeed anytime I hold my hands together. This is purportedly chi. I guess this cannot be measured or explained'. This communication illustrates the depth of the problem in appraising feng shui claims and proposing educational examination. 


\section{Animal Magnetism²}

The history of science provides a well-documented episode that mirrors so much of contemporary chi-based 'science', and from which many methodological and social lessons can be learnt. This is the case of 'Animal Magnetism' promoted in the eighteenth century by the German physician Franz Anton Mesmer (1734-1815). He was well educated in philosophy, theology and law; and then studied medicine at the University of Vienna, where in 1766 he completed a doctoral thesis 'Physical-Medical Treatise on the Influence of the Planets' (Mesmer, 1766/1980).

Mesmer's early Viennese studies and clinical experiences led him to postulate an allpervasive, superfine, invisible, cosmic 'fluid' that held the solar system together and enabled Newton's gravitational forces to operate at a distance. But beyond astronomical duty, this fluid also seeped into human and animal bodies affecting their constitution and behavior. His 1766 doctoral thesis launched 'animal magnetism' on to the Western scientific and medical stage:

There is a force which is the cause of universal gravitation and which is, very probably, the foundation of all corporal properties; a force which actually strains, relaxes and agitates the cohesion, elasticity, irritability, magnetism, and electricity in the smallest fluid and solid particles of our machine, a force which can, in this report, be called animal gravity. (Mesmer, 1766/1980, p.14)

By 1775 , in a letter to Dr. A.M. Unzer, Mesmer had changed his terminology to animal magnetism and reported on many properties of the fluid and on its clinical manipulation by natural and artificial magnets: 'Menstrual periods and hemorrhoids were restored to their normal condition ... I cured all kinds of hypochondriac, convulsive, and hysterical irregularities' (Mesmer, 1775/1980, p.28). Animal magnetic fluid could be manipulated by magnets because of its 'extreme subtlety and similarity to nervous fluid' (Mesmer, 1775/1980, p.29). And the fluid could be transferred from doctor to patient over distances:

Without any direct communication and from a distance of eight to ten feet, more over being hidden behind a man or a wall, I roused jolts in another part of the patient that I wanted to, and with a pain as ardent as if one had hit her with a bar of iron. (Mesmer, 1775/1980, p.28)

In 1778 Mesmer left Vienna and set up a large medical and healing practice in preRevolutionary Paris. Newspapers of the time had stories headed: 'Everyone is occupied with mesmerism', 'The great subject of all conversations in the capital is still animal magnetism', 'Men, women, children, everyone is involved, everyone mesmerizes' (Darnton, 1968 , p.40). In most major cities 'Societies of Harmony' were founded to promote magnetic therapy. But there was professional opposition, and by 1781 Mesmer had 'insulated' his theory by claiming that animal magnetism could only be detected by a hitherto unrecognized sixth 'artificial' sense; something he had and could only be enabled by training: 'it must be transmitted by experience. Experience alone can render my theory intelligible' (Mesmer, 1781/1980, p.135).

Enough Parisian physicians and natural philosophers regarded Mesmer as a charlatan, or perhaps simply as an out-of-town competitor, that in 1784 they succeeded in having

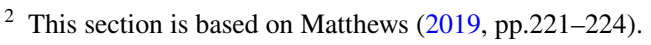


Louis XVI establish a Royal Commission, chaired by Benjamin Franklin and including Antoine Lavoisier, to investigate his claims. It issued, just five years before the beginning of the Revolution, and a decade before Louis' beheading, 'The Franklin Report' (Franklin et al., 1784/2014). ${ }^{3}$

The commissioners recognized, in the way that most current feng shui and alternative medicine advocates do not, that merely testing the effectiveness of treatment did not advance the main question because many illnesses cure themselves, placebo effects are rampant, and cures have ultimately to be linked to specific mechanisms in order to be recognized as scientific. Not surprisingly, given Franklin's and Lavoisier's involvement, the Commission was sensitive to methodological issues:

The art of drawing conclusions from experiments and observations consists in evaluating the probabilities and in judging whether they are large enough, or numerous enough, to amount to proof. This type of calculation is more complicated and more difficult than one thinks; it demands great sagacity and is, in general, beyond the powers of most men. It is upon their errors in this type of calculation that is founded the success of charlatans, sorcerers and alchemists; and, in other times, of magicians, enchanters and all those who deceive themselves and attempt to prey on public credulity. (Franklin et al., 1784/2014, p.26)

And:

After having seen the effects at the public treatment it was necessary to disentangle their causes and to look for evidence of the existence and the utility of Animal Magnetism. Animal Magnetism can well exist without being useful, but it cannot be useful if it does not exist. (Franklin et al., 1784/2014, p.43)

They observed that:

Touchings, imagination, imitation, these are the real causes of the effects attributed to this new agent advertised under the name animal magnetism. The practice of magnetism consists of the art of increasing the imagination by degrees; gaze, pressure, touching seem to act as a preparation, the nerves begin to be agitated, imitations communicate and expand impressions. (Franklin et al., 1784/2014, p.36)

And: 'Magnetism seemed ineffective on those who submitted to it with some scepticism' (Franklin et al., 1784/2014, p.52). After much testing and examination their conclusion was comprehensive and damning:

The Commissioners, having recognized that this animal magnetic fluid cannot be perceived by any of our senses, that it has no effect, either on them or on the patients who are subjected to it; being assured that the pressures and touching occasion changes which are rarely favourable to the animal economy, and disturbances that are always disturbing to the imagination, having finally shown by decisive experiments that the imagination, with magnetism, produces convulsions, and that magnetism without imagination produces nothing, have concluded unanimously about the question of the existence and utility of magnetism, that nothing proves the existence of animal magnetism; that this non-existent fluid is consequently useless. (Franklin et al., 1784/2014, p.37)

${ }^{3}$ The context, composition, and functioning of the Commission is described in Darnton (1968, pp.62-64). 


\section{STEAM Curriculum Subject Areas and Topics}

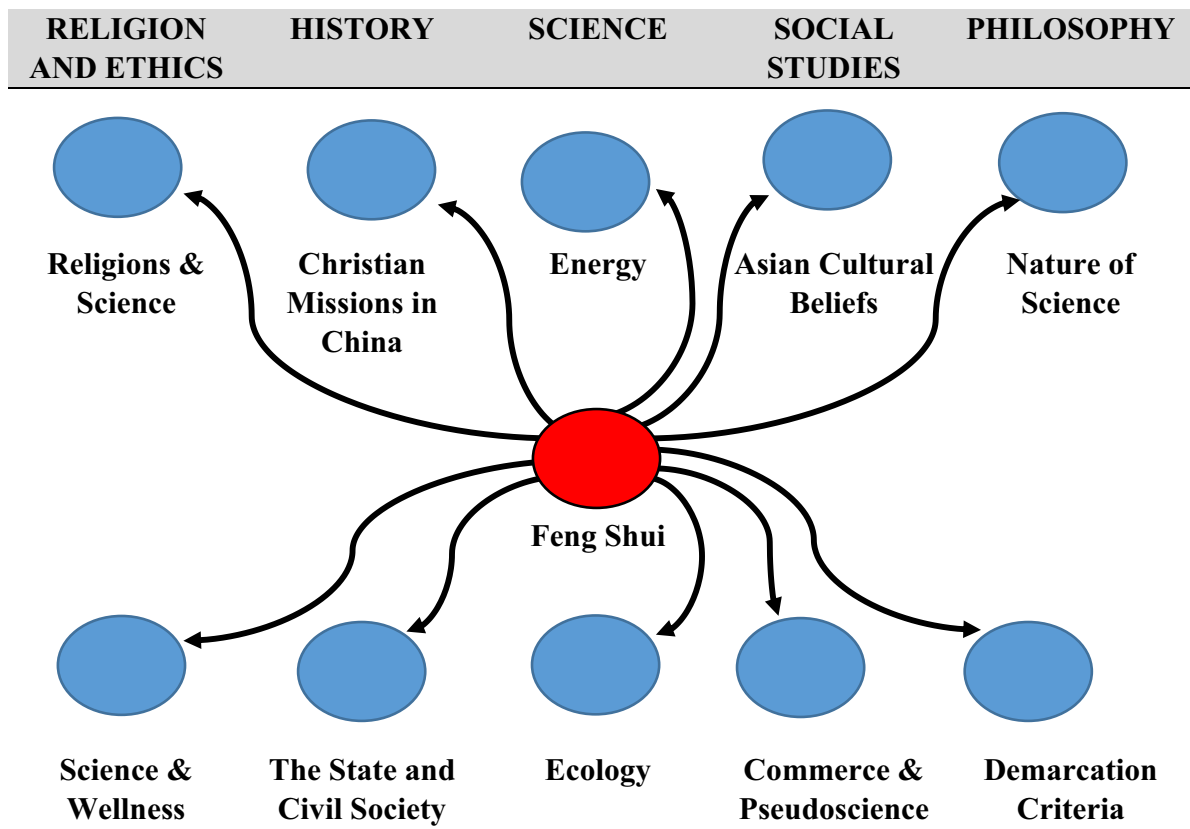

Fig. 1 STEAM curriculum subject areas and topics

And they ruled out the possibility of any refinement of Mesmer's theory because its ontological presuppositions were simply false, the presuppositions did not accord with how the world was:

If M. Mesmer announces a larger theory, it will only be more absurd; celestial influences are an old chimera whose falsity has been long recognized; all this theory can be judged in advance by that which magnetism necessarily has for its base, and it can have no reality because the animal fluid does not exist. (Franklin et al., 1784/2014, p.70).

They could have, but did not, point to the 'get out of jail' card that Mesmer had dealt himself by adding 'negative' animal magnetism to his ontology. Among his 27 Summary Propositions, is:

19. This opposing property also penetrates all bodies; it may likewise be communicated, propagated, stored, concentrated and transported, reflected by mirrors and propagated by sound; this constitutes not merely the absence of magnetism, but a positive opposing property. (Mesmer, 1779/1980, pp.67-68)

With Franklin and Lavoisier among its members, the Commission's methods reflected Enlightenment science (Hankins, 1985). This makes the Animal Magnetism episode instructive for contemporary scientists, philosophers, and students. The commissioners were not proto-positivists; they were not of the 'If we cannot see it, it is not 
there' school. They recognized that while unseen scientific entities and realities were legitimately inferred from observation, not all such inferences were warranted. Different Mesmerists pointed to gravitational attraction, magnetic fields, caloric, and electric phenomena to claim existence for their particular 'unseen', 'weightless', 'colourless' magnetic fluid. The Commissioners were conscious of needing to rule out the latter in a way that did not rule out the former; to rule out Mesmer but not Newton (Donaldson, 2005; Weyant, 1980). This has been an on-going philosophical task as documented in contributions to this thematic issue. At almost every point in the articulation and then evaluation of Mesmerism, there are parallels with feng shui: same story line, different characters. Reading the story, and thinking carefully about it, can be an effective part of science education. It could, for instance, prepare students for the multi-million dollar 'bio-magnetic' therapy business, more properly racket, that set up in the first decade of the current century. 'Therapeutic magnets' were widely sold, at an advertised price of USD89, in sporting and 'complementary medicine' shops.

\section{STEM or STEAM Teaching of Feng Shui}

What explicitly connects feng shui with science education is that, despite the seeming mysteriousness of its chi core, its absence from standard science texts and laboratories, its popular associations with divination, astrology, charms, and its exploitation in a wide range of fraudulent commercial practices its worldview is ostensibly naturalistic. In its own terms, it is scientific. Feng shui can legitimately, and with cultural and educational benefit, be appraised in science classes. Its classroom examination can illuminate important features of the nature of science, and the role of science in society and culture. Further, feng shui can be a rich topic for coordinated, cross-disciplinary teaching between different school faculties: science, history, social studies, philosophy, art, economics, and religion. The cross-disciplinary appraisal of feng shui is an excellent case-study for STEM (Science-Technology-Engineering-Mathematics) education and its Arts-augmented variant, STEAM education. A cross-disciplinary approach to the inclusion of feng shui in a STEM or STEAM curriculum could look like the following (Fig. 1):

\section{Conclusion}

The considered and informed examination of feng shui is a way for students to learn about the nature of science and other important social processes - the impact of marketing, the cultural determiners of gullibility, and so on. Minimally students should recognise that Feng Shui's ontology is evasive, ill-determined and unbound; and its epistemology is empiricist and subjectivist. Such learning can be science education's contribution to the cultural health of society. Cultural health is inversely related to the degree that gullibility, credulity, superstition, and unwarranted beliefs prevail in the society. The millions of feng shui websites and consultants are in it for the money; the hard-earned money of adults and school leavers. A half-decent HPS-informed science education can give citizens some facility to judge just what they are getting for their feng shui money, and how it might be better spent on more firmly established health, 
exercise and construction practices. And the same learning should flow over to appraisal of the myriad other scams and exploitative commercial ventures that prey upon the young and the old.

The quality of such learning will depend on the quality, sensitivity and informedness of the teaching. In the classroom consideration of feng shui, and its chi-based worldview, the issues should be problematized, questions asked, claims examined, and alternatives investigated. Over time, and by engagement with problematic aspects of feng shui, the strengths and advantages of a scientific outlook, of respecting and seeking out evidence, should become apparent to students. Hopefully the essays in this thematic issue will contribute to a deeper appreciation by teachers of the complex philosophical, cultural and educational dimensions of feng shui. As editor of the thematic issue, I acknowledge and appreciate the diligent and informed reviewing of all initially submitted manuscripts by 33 scholars (philosophers, educators, psychologists, and anthropologists) from 12 countries. Authors also value the many suggestions made and corrections required.

Conflict of Interest The author declares no conflict of interest.

\section{References}

Baehr, J. (Ed.). (2016). Intellectual virtues and education essays in applied virtue epistemology. Routledge.

Brown, S. (2005). The Feng Shui bible: The definitive guide to practising Feng Shui. Octupus Publishing Group.

Bunge, M. (2001). Philosophy in crisis: The need for reconstruction. Prometheus Books.

Bunge, M. (2000). 'Energy: Between Physics and Metaphysics'. Science \& Education, 9(5), 457-461.

Coopersmith, J. (2010). Energy, the subtle concept: The discovery of Feynman's Blocks from Leibniz to Einstein. Oxford University Press, Oxford.

Darnton, R. (1968). Mesmerism and the end of the enlightenment in France. Harvard University Press.

Department of Energy (DoE) USA. (2012). Energy literacy: Essential principles and fundamental concepts for energy education. US Department of Energy.

Derksen, A. A. (1993). The seven sins of demarcation. Journal for General Philosophy of Science, 24, 17-42.

Donaldson, I. M. L. (2005). Mesmer's 1780 proposal for a controlled trial to test his method of treatment using "animal magnetism." Journal of the Royal Society of Medicine, 98(12), 572-575.

Franklin, B., Le Roy, M., Bailly, S. J.-S., Guillotin, J.-I. de Bory, d'A. \& Lavoisier, A.: 1784/2014, 'Report of the commissioners charged by the king with the examination of animal magnetism'. In I.M.L. Donaldson (trans. \& ed.) The Reports of the Royal Commission on Mesmer's System of Animal Magnetism and Other Contemporary Documents, James Lind Library and Royal College of Physicians of Edinburgh, pp. 39-76

Hankins, T. L. (1985). Science and the enlightenment. Cambridge University Press.

Kwok, D. W. Y. (1965). Scientism in Chinese thought: 1900-1950. Yale University Press.

Lange, M. (2001). The most famous equation. Journal of Philosophy, 98, 219-238.

Laven, M. (2011). Mission to China: Matteo Ricci and the Jesuit Encounter with the East. Faber \& Faber.

Lee, J.-H. (2006). 'The research about interpreting the doctrine of the five natural elements of Yin and Yang'. Journal of the New Korean Philosophical Association, 46, 335-349.

Matthews, M. R. (2019). Feng Shui: Teaching about science and pseudoscience. Springer.

Mesmer, F.A.: 1766/1980, 'Physical-medical treatise on the influence of the planets'. In G. Bloch (ed. \& trans.), Mesmerism: A translation of the original scientific and medical writings of F.A. Mesmer, Kaufmann, Los Altos, CA., pp.3-29. 
Mesmer, F.A.: 1775/1980, 'Letter to A.M. Unzer, Doctor of Medicine, on the medicinal usage of the magnet'. In G. Bloch (ed. \& trans.), Mesmerism: A translation of the original scientific and medical writings of F.A. Mesmer, Kaufmann, Los Altos, CA., pp.25-29.

Mesmer, F.A.: 1779/1980, 'Dissertation on the discovery of animal magnetism'. In G. Bloch (ed. \& trans.), Mesmerism: A translation of the original scientific and medical writings of F.A. Mesmer, Kaufmann, Los Altos, CA., pp. 43-70.

Mesmer, F.A.: 1781/1980, 'Extract from Précis Histrorique des Faitss Relatifs au Magnétisme Animal'. In G. Bloch (ed. \& trans.), Mesmerism: A translation of the original scientific and medical writings of F.A. Mesmer, Kaufmann, Los Altos, CA., pp.135-37

Ministry of Science and Technology of CCP (MST): 2016, Circular of the Ministry of Science and Technology and the Propaganda Department of the CPC Central Committee on Printing and Distributing the Benchmark of Civic Scientific Literacy in China, https://www.most.gov.cn/fggw/zfwj/zfwj2016/ 201607/t20160701_126220.htm. Accessed 10 Dec 2020.

Needham, J.: 1978, The shorter science and civilization in China, vol.1, abridgement by C.A. Ronan, Cambridge University Press.

NGSS Lead States. (2013). Next Generation Science Standards. National Academies Press.

Ricci, M.: 1615/1953 On the Christian Mission among the Chinese. In L.L. Gallagher (1953), China in the sixteenth century: The Journals of Matthew Ricci, 1583-1610, Random House.

Sherman, T.F. (2018). Energy, entropy, and the flow of nature. Oxford University Press, Oxford.

Sivin, N. (1984). Why the scientific revolution did not take place in China - or Didn't It? In E. Mendelshohn (Ed.), Transformation and Tradition in the Sciences (pp. 531-554). Cambridge University Press.

Tobin, K. (2015). 'Connecting science education to a world in crisis.' Asia-Pacific Science Education, 1, 2. https://doi.org/10.1186/s41029-015-0003-z

Wang, R. R., \& Ding, W. (2010). Zhang Zai's theory of vital energy. In J. Makeham (Ed.), Dao Companion to Neo-Confucian Philosophy (pp. 39-57). Springer.

Weyant, R. G. (1980). Protoscience, pseudoscience, metaphors and animal magnetism. In M. P. Hanen, M. J. Osler, \& R. G. Weyant (Eds.), Science, pseudoscience and society (pp. 77-114). Wilfrid Laurier University Press.

Xin, Yan. (2015). Secrets and benefits of internal Qigong cultivation. Amber Leaf Press.

Yan, Xin, Lu, F., Jiang, H., Cao, W., Xia, Z., Shen, H., Wang, J., Dao, M., Lin, H. \& Zhu, R. (2002). Journal of Scientific Exploration 16(3), 381-411

Yoon, H.-K. (2006). The culture of Fengshui in Korea: An exploration of East Asian geomancy. Rowan \& Littlefield.

Zagzebski, L. (1996). Virtues of the mind: An inquiry into the nature of virtue and the ethical foundations of knowledge. Cambridge University Press.

Zhang, D. (2002). Key concepts in Chinese philosophy, (translated and edited by Edmund Ryden). Foreign Languages Press.

Publisher's Note Springer Nature remains neutral with regard to jurisdictional claims in published maps and institutional affiliations. 